\title{
A ARTICULAÇÃO ENTRE AS CATEGORIAS DE GÊNERO, DEFICIÊNCIA E EDUCAÇÃ̃O SUPERIOR NA PRODUÇÃO CIENTÍFICA BRASILEIRA
}

\author{
Natali Esteve Torres ${ }^{1}$ \\ Fabiane Adela Tonetto Costas ${ }^{2}$
}

\begin{abstract}
Resumo: A Educação Superior brasileira, fundada sob a lógica da ciência e poder, foi historicamente constituída com influência de setores como a Igreja, o Estado e o mercado, pensada para formação de quadros para estes setores e nunca para o atendimento de interesses sociais. Políticas como as de reservas de vagas adentram o cenário nacional em 2007, em termos históricos, isto é extremamente recente para grupos sociais que foram apartados destas instituições. O objetivo deste estudo é mapear o que vem sendo produzido cientificamente no Brasil, de 2011 até 2017, referente às categorias de gênero, deficiência e educação Superior através da elaboração de um Estado do conhecimento, sendo esta a metodologia utilizada. Desse modo, realizaram-se buscas nos principais portais digitais de divulgação da produção científica brasileira das categorias- já citadas- de forma isolada e posteriormente associadas entre si. Uma análise inicial apresentou um contingente de 617 trabalhos realizados entre 2011 e 2018 sendo selecionados mais de 74 trabalhos para leitura mais aprofundada e discussão. Os estudos mais elaborados ainda são aqueles que tratam as questões de gênero e deficiência de forma isolada e demonstram o quanto as temáticas mencionadas fazem parte das produções periféricas das ciências humanas, sobretudo evidenciam a dificuldade da inserção da discussão da deficiência estar atrelada a estudos de gênero, étnico raciais, de classe e orientação sexual, ocasionando uma maior invisibilidade a estas pessoas mesmo em meio às minorias sociais.
\end{abstract}

Palavras-chave: Educação Superior. Gênero. Deficiência.

\section{THE ARTICULATION BETWEEN THE CATEGORIES OF GENDER, DISABILITY AND HIGHER EDUCATION IN THE BRAZILIAN SCIENTIFIC PRODUCTION}

\begin{abstract}
The Brazilian Higher Education, founded under the logic of science and power, was historically constituted with influence from sectors such as the Church, the State and the market, designed to train cadres for these sectors and never to attend to social interests. Policies such as vacancy reservations enter the national scenario in 2007, in historical terms, this is extremely recent for social groups that have been removed from these institutions. The objective of this study is to map what has been produced scientifically in Brazil in the last decade, referring to the categories of gender, disability and higher education through a state of knowledge. As a methodology we use the state of knowledge. In this way, searches were carried out in the main digital portals for the dissemination of Brazilian scientific production of isolated and later associated categories. An initial analysis presented a contingent of 617 works carried out between 2011 and 2018, being selected more th an 74 papers for further reading and discussion. The most elaborate studies are still those that treat the issues of

\footnotetext{
${ }^{1}$ Mestranda do Programa de Pós-Graduação em Educação - PPGE. Universidade Federal de Santa Maria. Santa Maria. RS. Brasil

${ }^{2}$ Professora do Programa de Pós-Graduação em Educação - PPGE. Universidade Federal de Santa Maria. Santa Maria. RS. Brasil.
} 


\section{Universidade do Extremo Sul Catarinense \\ Revista Ibero-Americana de Humanidades, Ciências e \\ Educação \\ unesc

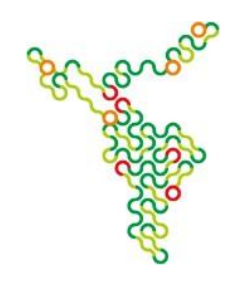

gender and disability in isolated ways and demonstrate how much the themes mentioned are part of the peripheral productions of the human sciences, especially the difficulty of inserting the discussion of disability be tied to gender studies, ethnicity, class and sexual orientation leading to greater invisibility to these people even in the midst of social minorities

Keywords: College education. Genre. Deficiency.

\section{INTRODUÇÃO}

O ingresso de pessoas com deficiência na Educação Superior é uma conquista recente e foi garantido a partir da política de reserva de vagas. A Lei de Cotas que institui a reserva de vagas nas universidades públicas e institutos federais do país foi efetivada em 29 de agosto de 2012 através da Lei 12.711. Se observarmos especificamente o contingente de pessoas com deficiência que ocupam vagas em universidades e institutos federais temos dados por vezes imprecisos. Isto porque, muitas são as questões existentes entre o acesso e as condições de permanência dessas pessoas na Educação Superior revelando é uma disparidade entre o número de acesso e o número de estudantes que efetivamente conseguem terminar os cursos que ingressam.

Para pensar as questões propostas por este estudo, faremos uma análise no que tange às questões de gênero na sociedade, suas lutas e conquistas no âmbito político, cultural e social. Observando sob o aspecto do gênero faremos um recorte no intuito de observar as mulheres com deficiência enquanto sujeitos ativos nesse cenário e partícipes desses espaços educacionais dos quais estiveram historicamente apartadas.

Dentro desse contexto, busca-se investigar quais as articulações entre as categorias de gênero, deficiência e Educação Superior na produção cientifica brasileira, pois entendemos que essas categorias não podem ser observadas separadamente, correndo o risco de não compreender de forma profunda a realidade dessas pessoas nesse contexto.

\section{Percurso metodológico}

Como metodologia adotada para esta investigação, optamos pela realização de um estado do conhecimento, compreendendo que se configura como uma possibilidade viável para responder nosso 


\section{Universidade do Extremo Sul Catarinense \\ Revista lbero-Americana de Humanidades, Ciências e \\ Educação \\ unesc

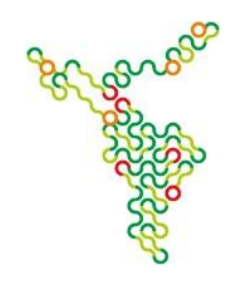

objetivo. Ferreira (2002 p.259) afirma que a construção do estado de conhecimento é uma forma desafiadora de tomar ciência sobre o que já foi produzido para depois buscar o que ainda não foi feito, além de dedicar maior atenção a um número considerável de pesquisas realizadas e de dar conta de determinado saber para divulgá-lo a sociedade.

Morosini e Fernandes (2014) entendem como estado do conhecimento "a identificação, registro, categorização que levem à reflexão e síntese sobre a produção cientifica de uma determinada área, em um determinado espaço de tempo, congregando periódicos, teses, dissertações e livros sobre uma temática específica". Segundo as autoras uma das principais características é destacar as contribuições da presença do novo no estudo que está sendo realizado. As autoras destacam algumas etapas metodológicas para a escrita do estado do conhecimento, sendo elas: (1) Identificação da temática do estudo, da pergunta de partida, e das palavras-chave ligada ao tema. (2) Leitura e discussão sobre produção científica. (3) Identificação de fontes e constituição do corpus de análise.

Portanto, realizou-se um estado do conhecimento no período de tempo são de 2012 até 2017, essas datas justificam-se por tratarem-se do período de aprovação das Políticas de Ações Afirmativas nas principais Universidades nacionais, assim, entende-se a inserção das pautas afirmativas no cenário da pesquisa acadêmica nacional e consequentemente, maior produção na área.

É possível observar, através das datas das publicações selecionadas, o crescente avanço nessas discussões, o que é positivo, pois o Brasil carece cada vez mais da ampliação dessas discussões para que venha se desnaturalizar conceitos advindos do senso comum assim como efetivar políticas públicas que venham a sanar possíveis desigualdades.

Os portais em que se realizou a pesquisa foram: Periódicos CAPES, Portal Scielo, Google Acadêmico, no período de maio a dezembro de 2017. As palavras/temáticas utilizadas para busca nos três portais foram: (1) Pessoa com deficiência na Educação Superior e Inclusão na Educação Superior, (2) Mulheres na Educação Superior, (3) gênero e deficiência e (4) mulheres com deficiência na Educação Superior.

As pesquisas localizadas foram tabeladas com os seguintes dados: Título, Local que a pesquisa foi produzida, assunto e ano. Nos três portais de busca, foram realizadas as leituras dos resumos, dentre eles, os que realmente abordavam assuntos relacionados a temática de busca foram localizados 74 trabalhos. 


\section{Universidade do Extremo Sul Catarinense}

Revista Ibero-Americana de Humanidades, Ciências e

Educação

Unesc Produção e democratização do conhecimento na llbero-América

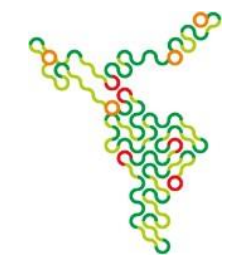

\section{Análise do material}

De acordo com o material encontrado, foi elaborado uma tabela uma os títulos dos trabalhos observados, local da produção, ano e principal assunto abordado, como a analise gerou um contingente de XX trabalhos observados, não será possível anexar esse material completo, apenas, uma mais simplificada que contém a palavra chave pesquisada, o portal de busca, a quantidade de material gerada e quais efetivamente falavam sobre o assunto pesquisado.

\begin{tabular}{|c|c|c|c|}
\hline \multicolumn{4}{|c|}{ Período da busca: 2012 - 2017} \\
\hline PALAVRAS-CHAVE & $\begin{array}{l}\text { PORTAL DE } \\
\text { BUSCA }\end{array}$ & $\begin{array}{l}\text { QUANTIDADE DE } \\
\text { TRABALHOS } \\
\text { ENCONTRADOS - } \\
\text { LEITURA DE } \\
\text { RESUMOS }\end{array}$ & $\begin{array}{c}\text { TRABALHOS } \\
\text { SELECIONADOS } \\
\text { APÓS LEITURA } \\
\text { DO RESUMO }\end{array}$ \\
\hline \multirow{3}{*}{$\begin{array}{c}\text { Pessoa com } \\
\text { deficiência no } \\
\text { Educação Superior e } \\
\text { Inclusão na } \\
\text { Educação Superior }\end{array}$} & Periódico CAPES & 171 & 35 \\
\hline & Scielo & $\begin{array}{c}180 \\
\text { primeiros títulos de } \\
\text { trabalhos por ordem de } \\
\text { relevância }\end{array}$ & 5 \\
\hline & Google acadêmico & 5 & 5 \\
\hline \multirow{3}{*}{$\begin{array}{c}\text { Mulheres na } \\
\text { Educação Superior }\end{array}$} & Periódico CAPES & 2 & 2 \\
\hline & Scielo & 14 & 14 \\
\hline & Google Acadêmico & 4 & 4 \\
\hline \multirow[t]{3}{*}{ Gênero e deficiência } & Periódico Capes & 7 & 7 \\
\hline & Scielo & 90 & 1 \\
\hline & Google acadêmico & $\begin{array}{c}50 \text { primeiros por } \\
\text { ordem de relevância }\end{array}$ & 1 \\
\hline Mulheres com & Periódico CAPES & 51 & 0 \\
\hline deficiência e & Scielo & 0 & 0 \\
\hline Educação Superior & Google acadêmico & 100 primeiros & 0 \\
\hline
\end{tabular}




\section{Universidade do Extremo Sul Catarinense \\ Revista Ibero-Americana de Humanidades, Ciências e \\ Educação \\ unesc

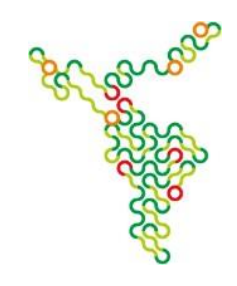

No Periódico CAPES, o assunto: "pessoa com deficiência no Educação Superior e Inclusão na Educação Superior" no período de 2012 a 2017, apresentou 171 resultados, após a leitura dos resumos, foram selecionados 35 trabalhos que estavam relacionados com o assunto. Dentre eles, 15 abordavam assuntos relacionados a práticas inclusivas em instituições de Educação Superior, 10 tinham como foco principal a questão as Políticas de Inclusão, 7 observavam questões de acessibilidade e 3 questões relacionadas a formação de professores.

No Scielo, esse mesmo tópico - pessoa com deficiência e Educação Superior / ou inclusão não gerou nenhum resultado. Já no Google Acadêmico, foram observados os 180 primeiros títulos de trabalhos por ordem de relevância no mesmo período de data, dentre eles, os que não estavam repetidos das outras buscas e realmente faziam parte da temática foram selecionados 5 , pois grande parte deles ou estava citada na busca do Periódico Capes ou dizia respeito a inclusão social, racial ou escolar.

Dos cinco trabalhos selecionados no Google acadêmico, três referem-se a políticas públicas, um a práticas inclusivas e um a questões relacionadas aos papeis de gestão no desenvolvimento e fortalecimento de práticas inclusivas.

Flores (2017) produziu um estudo com o intuito de pensar questões relativas a democratização do Ensino Superior no Brasil desde o Brasil colônia até os tempos atuais. A pesquisa bibliográfica realizada pelo autor não tem o objetivo de relatar os problemas que houveram na implementação da democratização, mas entender os avanços obtidos a partir de uma preocupação tardia em reparar desigualdades históricas de determinados grupos da sociedade brasileira.

O segundo tópico, que foi a busca por estudos que abordassem mulheres na Educação Superior, no mesmo período e portais de busca, gerou uma seleção de 20 trabalhos tabelados, foram observados os que estavam aparecendo pela primeira vez na busca.

No Periódico Capes foram encontrados dois trabalhos de 2015, um sobre a presença de mulheres negras em espaços públicos, tratando questões específicas de gênero e raça e outro sobre mulheres em espaços de gestão em universidades mexicanas.

No Scielo foram encontrados 14 trabalhos da temática, seis deles, internacionais. Sete das pesquisas selecionadas falavam mais especificamente de questões relacionadas a trabalho e desigualdades. Cinco, abordavam questões de discriminação ou desigualdade de gênero nos espaços 


\section{Universidade do Extremo Sul Catarinense \\ Revista Ibero-Americana de Humanidades, Ciências e \\ Educação \\ unesc

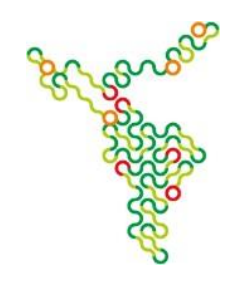

universitários enquanto acadêmicas, principalmente em cursos historicamente construídos como masculinos ligados a ciência e tecnologia.

No Google acadêmico foram encontrados 4 trabalhos diferentes aos relacionados anteriormente, sendo que estes tratam questões relacionadas ao empoderamento feminino nos espaços da Educação Superior, um deles aborda as implicações e desafios de mulheres em cargos de gestão nas universidades, outro sobre o empoderamento de mulheres camponesas com o acesso à Educação Superior, um apenas sobre autonomia feminina frente aos espaços sociais e por fim, um que realiza uma revisão histórica em relação à mulher no ensino superior e a reversão do hiato de gênero nas universidades brasileiras nas últimas décadas.

A terceira categoria de busca realizada nos portais - Gênero e deficiência foi possível selecionar mais 10 trabalhos de produção na área.

No Periódico Capes, dos 7 trabalhos selecionados, 2 deles falam sobre a sexualidade da mulher com deficiência, um sobre a constituição do corpo da mulher deficiente física, na perspectiva dos estudos culturais, dois sobre questões relacionadas a saúde da mulher com deficiência e como ela é atendida nos espaços públicos de promoção a saúde. E, um sobre indicadores de indicadores educacionais no Brasil observando recortes de gênero, raça, classe e deficiência.

No Scielo, a busca por gênero e deficiência gerou um total de 90 resultados. Dentre eles, os mais relevantes já estavam mencionados nas buscas anteriores, um deles não estava citado e trata sobre gênero e sexualidade da mulher com deficiência intelectual, um estudo de caso realizado em uma Associação de Pais e Amigos dos Excepcionais-APAE.

Por fim, no Google acadêmico foi selecionado um trabalho, publicado em Portugal em 2014 sobre psicologia, sexualidade e deficiência na perspectiva dos direitos humanos, produzida por Mello e Nuernberg (2014). Do total dos 74 trabalhos tabelados, muitos deles ricos em informações importantes para este estudo, nenhum deles relaciona as três categorias - gênero, deficiência e Educação Superior - o que justifica a relevância de pesquisas que articulem essas análises, devido a necessidade de pensarmos tais questões na mesma categoria, uma vez que as ações afirmativas tendem a trazer a cada ano um contingente maior de mulheres para os espaços acadêmicos e a discussão de gênero sob essa perspectiva ainda é periférica e inicial na produção científicado Brasil. Embora nenhum desses trabalhos fale sobre questões de gênero e deficiência na Educação Superior, vale destacar o artigo publicado em 2014, escrito por Mello e Nuernberg, intitulado: Gênero 


\section{Universidade do Extremo Sul Catarinense \\ Revista Ibero-Americana de Humanidades, Ciências e \\ Educação \\ unesc

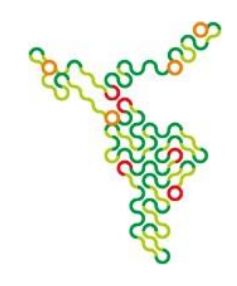

e deficiência, intersecções e perspectivas. No material, os autores destacam o fato de da deficiência ainda ser uma temática periférica tanto nas ciências humanas quanto nas construções de teorias feministas. Após um apanhado histórico da inserção de estudos relacionados à deficiência nas ciências humanas os autores estabelecem interfaces conceituais onde é possível articular eixos entre os campos de estudos feministas e estudos sobre as deficiências, sendo eles: (1) o pressuposto da desnaturalização do corpo, (2) a dimensão identitária do corpo e, (3) a ética feminista da deficiência e do cuidado. Destacam o quão são iniciais no Brasil estudos que articulem os dois campos de conhecimento e justificam com isso a baixa participação de mulheres com deficiência em movimentos feministas uma vez que ainda tão negligenciadas em suas questões da deficiência acabam deixando a margem seus outros sujeitos políticos.

\section{Discussão dos resultados:}

Ao efetivar-se a busca descrita, verificou-se que temas como pessoas com deficiência na Educação Superior/Inclusão, embora sejam recentes nos contextos das universidades já começam a ser discutidos de forma mais efetiva dentro do país com trabalhos produzidos nas regiões Norte, Nordeste, Sudeste e Sul. Enquanto busca que contemplou gênero e deficiência apontou para um número bastante inferior, em sua grande maioria, trabalhos que trabalham sob a perspectiva do modelo clínico da deficiência, com apenas um dos vinte trabalhos selecionados observar a deficiência pelo modelo social.

O não aparecimento de nenhum estudo que observasse as questões da deficiência sob aspectos sociais, nesse caso a categoria de gênero como importante para compreender os fenômenos educacionais e de aprendizagem, é algo que precisa ser destacado, visto que mulheres com deficiência estão inseridas nas instituições como estudantes e trabalhadoras antes da política de cotas. Para compreender esse contexto, faz-se necessário retomar a trajetória histórica da educação das mulheres, pois, como afirma Louro (2004 p.372) "seria uma simplificação grosseira compreender a escolarização de homens e mulheres como processos únicos", além de evidenciar que divisões de classe, etnia e raça desempenham um importante papel nas formas de educação utilizadas para transformar crianças em homens e mulheres.

As mulheres brasileiras enfrentaram um processo para o acesso à escolarização, relembrando que a escolarização que lhes foi destinada vem no intuito de fortalecer os papeis de mãe e esposa, 


\section{Universidade do Extremo Sul Catarinense \\ Revista Ibero-Americana de Humanidades, Ciências e \\ Educação \\ unesc

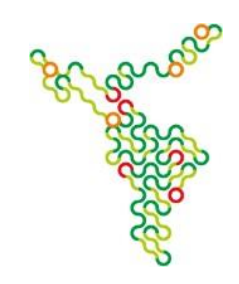

colocando-as como as responsáveis por fazerem dos homens "bons ou maus". (LOURO, 2004). Foi apenas no chamado Pacto Populista (1945-1964) que o Estado se viu obrigado a conter a pressão popular que, se demonstrava crescente pela democratização do ensino e, ao mesmo tempo, desejava mantê-lo de forma aristocrática.

Em um contexto de expansão e democratização do ensino e como resultado de pressões externas, é implementada a Lei de Diretrizes e Bases de 1961 que previa a equivalência de todos os cursos de grau médio, abrindo a possibilidade das mulheres que faziam magistério disputarem os vestibulares. (BELTRÃO E ALVES, 2009).

Com a expansão da industrialização no Brasil, cresce a demanda por investimentos em uma educação que vise à profissionalização, assim, os governos pós década de sessenta, expandem as oportunidades de acesso, pois isso representava uma demanda nacional.

Quando pensamos em mulheres, retomamos uma "dupla desvantagem" histórica e social que esse grupo possui. Essa “dupla desvantagem” é explanada na teoria feminista para exemplificar a experiência social da mulher com deficiência, assim como mencionam Mello e Nuemberg.

\footnotetext{
"No caso das mulheres, é recorrente na literatura feminista o argumento que evidencia a "dupla desvantagem" com que vivem as mulheres com deficiência em relação à participação social, direitos sexuais e reprodutivos, educação, trabalho e renda. Ao se constituírem mutuamente e se retroalimentarem, os efeitos do duplo estigma potencializam a exclusão das mulheres com deficiência, processo que se complexifica ainda mais quando cruzado com outras categorias como raça/etnia e classe. De todo modo, o que se quer ressaltar aqui é que, se tendemos hoje a falar de masculinidades e feminilidades, é preciso ressaltar a deficiência como componente do espectro de possibilidades dessas posições de gênero plurais. "MELLO E NUEMBERG (2012 p.641)
}

Gonzales (1984) afirma que quem possui o privilégio social possui o privilégio epistêmico, assim acreditamos que no momento que determinado grupo não é mencionado, lembrado e/ou observado, ele deixa de existir epistemologicamente, dificultando ainda mais as reflexões sobre suas condições sociais.

Embora pareça que falamos em um público pequeno ou reduzido há um grande número de mulheres com deficiência nas instituições educacionais brasileiras. De acordo com o Ministério da Educação em 2014 estavam matriculadas 698.768 estudantes com algum tipo de deficiência nas escolas públicas e privadas, já na Educação Superior do país a quantidade de matrículas de pessoas 


\section{Universidade do Extremo Sul Catarinense \\ Revista Ibero-Americana de Humanidades, Ciências e \\ Educação \\ unesc

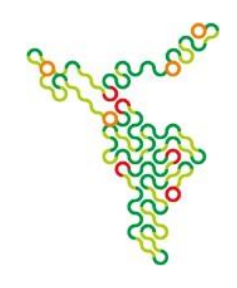

com deficiência aumentou 933,6\% entre 2000 e 2010 de acordo com dados divulgados pelo Ministério da Educação. Estudantes com deficiência passaram de 2.173 no começo do período para 20.287 em 2010, sendo que 6.884 desses alunos são da rede pública e 13.403 da particular.

Mesmo as estatísticas não mencionando a divisão de gênero em escolas e universidades esses dados representam um número significativo que precisa ser observado, principalmente se considerarmos os argumentos apresentados anteriormente em defesa de uma análise que observe as categorias de gênero, raça, classe e deficiência com o intuito de compreender de maneira mais significativa o contexto e vivências dessas pessoas. Sob esse aspecto pensamos uma segunda causa possível para a invisibilidade dessas pessoas na produção científica.

Acredita-se, diante do foi apresentado, nos estudos pesquisados, que há uma dificuldade em pensar as categorias de gênero, deficiência de forma atrelada. Há uma preponderância em estudos que olham para a deficiência a partir do modelo clínico, compreendendo as diferenças entre homens e mulheres do ponto de vista biológico, quando isso acontece, a perspectiva social e histórica da categoria gênero é negligenciada, como se não houvesse diferença nos processos históricos e sociais de homens e mulheres com deficiência.

Por fim, fazemos outra inferência necessária, a Educação ainda não percebe como suas questões relacionadas à gênero e deficiência. As discussões acerca da educação, neste estudo, estão atreladas à função da escola. A escola e as universidades, pós ditadura militar e pós democratização, passam a ser o local onde todas as discussões se encontram, todas as demandas sociais se fazem presentes. A pobreza, a fome, as opressões relacionadas a gênero, raça/etnia, classe e condição física e psicológica se manifestam, se reproduzem ou se transformam. Ao longo de todo o século XIX, ela é transformada num elemento central de homogeneização linguística e cultural, de invenção da cidadania nacional, em suma, de afirmação do Estado-nação como alega Teodoro (2003). A escola se expande gradativamente e passa a atender um maior contingente de pessoas de diferentes classes sociais em uma lógica de atender a todos, como se fossem um só.

Essa lógica, própria de um tempo de homogeneização, tende mais a ver como iguais os diferentes, do que compreender a diferença em todos seus aspectos. As políticas que normatizam esses espaços também caminham nesse sentido, tomemos como exemplo a Política Nacional de Educação Especial na perspectiva da Educação Inclusiva de 2008 que em nenhum momento ao longo do texto faz algum tipo de ressalva a algum tipo específico de deficiência ou transtorno, como se a 


\section{Universidade do Extremo Sul Catarinense \\ Revista Ibero-Americana de Humanidades, Ciências e \\ Educação \\ unesc

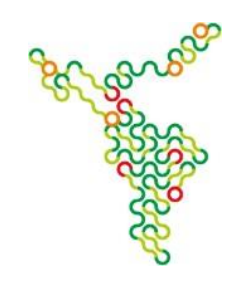

experiência escolar ou social da "pessoa com deficiência" fosse passível de generalizações "públicoalvo" da Educação Especial é observado como um todo, como se não houvesse especificidades socioculturais significativas no que tange à experiência escolar desses estudantes. Essa ideia nos afasta cada vez mais das singularidades, das categorias que nos permitem compreender posições sociais, pois estão associadas a toda uma história de dominação e exploração que mulheres, negros e negras e pessoas com deficiência enfrentaram ao longo da história.

\section{Considerações finais:}

Diante dos apontamentos realizados em relação às mulheres com deficiência a condição de deficiente traz consequências ocasionando, muitas vezes, uma dupla discriminação. Paralelo a isso, a independência financeira se coloca como uma forma de aquisição de autonomia e de exercício próprio da cidadania. Frente a isso, não nos cabe e nem é o objetivo deste estudo apontar vantagens ou desvantagens do ingresso desse público na Educação Superior, porém pensar como essas relações vêm sendo estabelecidas e como os pesquisadores envolvidos com temática da Educação e estão pensando essas questões.

Como foi mencionado anteriormente, muitos podem ser os fatores que distanciam tais assuntos desses campos do conhecimento, desde o formato que a educação está colocada, o fato dos cursos de formação desses profissionais e o paradigma clínico/social que as teorias observam a pessoa com deficiência e que as instituições educacionais vivenciam fortemente, pois ainda estão muito vinculadas a perspectivas que observam esses sujeitos sob os rótulos clínicos, muitas vezes desconsiderando questões como classe social, gênero, raça, etnia.

Tentar minimamente observar tais temas dentro de uma mesma história e sujeitos torna-se desafiador pela própria discussão ser tão inicial e sem referências sólidas. Cabe-nos, portanto, enquanto pesquisadores do campo da Educação, questionar onde estão essas pessoas e como temos observado as questões próprias de nossos estudos sem inserirmos categorias como de raça e gênero, classe, uma vez que considerar as questões sociais, é fundamental para compreender de forma mais profunda a realidade dessas pessoas e como estas se constituem. 
Universidade do Extremo Sul Catarinense

Revista lbero-Americana de Humanidades, Ciências e

Educação

Unesc Produção e democratização do conhecimento na llbero-América

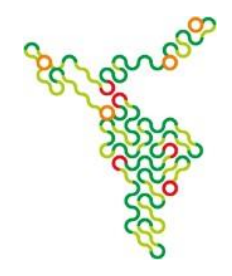
REFERÊNCIAS

BELTRÃO. K. I. ALVES. J. E. D. A redução do hiato de gênero na educação brasileira do século XX. Minas Gerais. 2009.

BRASIL. LEI 12.711 de 29 de agosto de 2012. Disponível em:

http://www.planalto.gov.br/ccivil_03/_ato2011-2014/2012/lei/112711.htm Último acesso em 13 de maio de 2019.

FERREIRA. N. S. A. As pesquisas denominadas 'estado da arte'. Revista 257 Educação \& Sociedade, ano XXIII, n o 79, Agosto/2002.

FLORES. R. S. A democratização do ensino superior no Brasil: uma breve história: da colônia a república. Revista Internacional de Educação Superior [RIEsup] São Paulo. 2017.

GONZALEZ, L. Racismo e sexismo na cultura brasileira. Revista Ciências Sociais Hoje, Anpocs, 1984.

LOURO, G. L. Mulheres na sala de aula. In. PRIORI, M. D. (org) História das Mulheres no Brasil. São Paulo. Editora Contexto, 2004.

MELLO. A. G. e NUERNBERG. A. H. e. Gênero e deficiência: Interseções e perspectivas. Estudos Feministas, Florianópolis, 20(3): 384, setembro-dezembro/2012.

MOROSINI, M. C. e FERNANDES. C. M. B. Estado do conhecimento: conceito, finalidades e interlocuções. Educação Por Escrito, Porto Alegre, v. 5, n. 2, p. 154-164, jul.-dez. 2014.

TEODORO, A. Globalização e Educação: políticas educacionais e novas formas de governação. Coleção Prospectiva. Vol. 9. Ed. Cortez. Brasil. 2003 